\title{
Gastric calcifying fibrous tumor: A clinicopathological study of nine cases
}

\author{
SHAN TIAN ${ }^{1}$, ZHI ZENG ${ }^{2}$, XIULAN PENG ${ }^{3}$ and WEIGUO DONG ${ }^{1}$ \\ Departments of ${ }^{1}$ Gastroenterology and ${ }^{2}$ Pathology, Renmin Hospital of Wuhan University, Wuhan, Hubei 430060; \\ ${ }^{3}$ Department of Oncology, The Fifth Hospital of Wuhan, Wuhan, Hubei 430050, P.R. China
}

Received May 23, 2018; Accepted September 6, 2018

DOI: $10.3892 /$ etm.2018.6892

\begin{abstract}
The aim of the present study was to analyze the clinicopathological characteristics presented in 9 cases of gastric calcifying fibrous tumor (CFT), and investigate the expressions and clinical implications of $\mathrm{G}$ protein-coupled estrogen receptor (GPER), estrogen receptor (ER) and vimentin in gastric CFTs. The clinical and pathological information of 9 patients with CFTs was investigated retrospectively. Subsequently, the expression of GPER, ER and vimentin were examined using immunohistochemistry, and a literature search for gastric CFT was conducted. The 9 patients were 40-71 years old with a mean age of 52.22 years, including 6 female and 3 male patients. Pathological features included dense hyalinized collagen fibers with a psammomatous body or dystrophic calcification, and the infiltration of scattered lymphocytes and plasma cells. Immunohistochemically, all cases expressed vimentin and GPER, whereas ER expression was negative. Using a database research, 25 studies regarding gastric CFT were identified, including 48 cases with a sex ratio (female:male) of 1.4:1. In addition, the number of female patients was twice the number of male patients in patients $<50$ years old, whereas the number was almost equal between women and men $\geq 50$ years of age. Gastric CFT is a benign lesion with a good prognosis and a predilection for female patients, particularly premenopausal women. Estrogen may serve a role in this female predominance, and this may be mediated by GPER rather than ER.
\end{abstract}

\section{Introduction}

Calcifying fibrous tumor (CFT) was first described as a 'childhood fibrous tumor with psammoma bodies' by Rosenthal and

Correspondence to: Professor Weiguo Dong, Department of Gastroenterology, Renmin Hospital of Wuhan University, 99 Zhang Zhi-Dong Road, Wuhan, Hubei 430060, P.R. China

E-mail: dongweiguo@whu.edu.cn

Key words: gastric calcifying fibrous tumor, immunohistochemistry, G protein-coupled estrogen receptor, estrogen receptor,clinicopathological features
Abdul-Karim (1) in 1988, but later studies demonstrated it may also occur among the adult population $(2,3)$. CFT is a rare but distinctive entity; it is a benign lesion that consists of abundant hyalinized collagen with psammomatous or dystrophic calcifications (4). CFTs primarily originate from the soft tissue, e.g. pleura and abdominal viscera; the stomach only rarely participates (5). CFT confined to the gastric wall is a rare and benign lesion, which usually presents without any gastrointestinal symptoms and is often detected incidentally (5). Gastric CFT is less likely to cause serious complications such as perforation or obstruction. In spite of its benign course and good prognosis, with known histological and immunohistochemical features, the exact pathogenic mechanism of this lesion remains elusive. Gastric CFT should be carefully differentiated from other spindle cell mesenchymal lesions involved in the stomach, such as inflammatory myofibroblastic tumor, sclerosing calcified gastrointestinal stromal tumor, schwannoma and IgG4-related sclerosing disease. Furthermore, given the rarity of gastric CFT (less than 50 cases reported to date), it is important to enhance the understanding of this lesion among clinicians. Therefore, the present study focused on exploring its clinical and pathological features by presenting 9 cases of gastric CFT, and reviewing previous English language articles regarding gastric CFT to determine whether this kind of tumor has a sex predilection. Furthermore, the current study aimed to analyze the possible association between female predominance and expression of $\mathrm{G}$ protein-coupled estrogen receptor (GPER).

\section{Subjects and methods}

The clinical information, relevant biochemical indicators [blood routine, tumor markers, $\mathrm{C}$ reactive protein, hepatitis $\mathrm{B}$ virus and Helicobacter pylori (HP)] and pathological features (gross examination and microscopic findings) of 9 patients with gastric CFT who had been admitted to the Department of Gastroenterology and Gastrointestinal Surgery at the Renmin Hospital of Wuhan University (Wuhan, China) between January 2015 and July 2018 were retrospectively reviewed. The present protocol was approved by the Institutional Review Board of the Renmin Hospital of Wuhan University, and all patient data was handled confidentially. All patients included in the present study provided written informed consent. The tumor slides from the 9 cases were collected from the Department of Pathology of the Renmin Hospital of Wuhan University. In 
addition, literature databases up to July 2018 were searched, including PubMed (www.ncbi.nlm.nih.gov/pubmed), Embase (www.embase.com), Scopus (www.scopus.com) and Google Scholar (scholar.google.com), for previously published English language articles regarding gastric CFT case reports or case series. The search terms were 'calcifying fibrous tumor AND gastric', and 'calcifying fibrous pseudotumor AND gastric'. Two authors reviewed potential studies, and any discrepancies were resolved by a third author.

Tumor specimens resected by endoscopic submucosal dissection (ESD) or gastric wedge excision (GWE) were fixed in $10 \%$ formalin solution for $4 \mathrm{~h}$ at room temperature and embedded in paraffin using routine methods. Deparaffinized sections with $4 \mu \mathrm{m}$ thickness were used for staining with hematoxylin and eosin (5 min for hematoxylin and $1 \mathrm{~min}$ for eosin). Immunohistochemical techniques were conducted according to the SP method as described previously (6). Deparaffinized sections with $4 \mu \mathrm{m}$ thickness were quenched in $3 \% \mathrm{H}_{2} \mathrm{O}_{2}$, then subjected to antigen retrieval in boiling citric acid ( $\mathrm{pH}$ 6.0) for 15 min and washed with PBS. Following incubation overnight with primary antibodies against GPER (ab39742; 1:200), estrogen receptor (ER; ab17230; 1:200) or vimentin (ab24525; 1:5,000; all from Abcam, Cambridge, $\mathrm{UK}$ ) at $4^{\circ} \mathrm{C}$, the sections were incubated for $15 \mathrm{~min}$ at room temperature with horseradish peroxidase-labeled polymer-conjugated secondary antibodies (MaxVision $^{\mathrm{TM}}$ kits; Maxim Bio, Fujian, China). The specimens were then incubated for $1 \mathrm{~min}$ at room temperature with diaminobenzidine (Maxim Bio). Finally, the sections were counterstained at room temperature with hematoxylin for $30 \mathrm{sec}$.

\section{Results}

Clinical characteristics of the 9 cases. Six patients (cases 4-9) originally attended the hospital for a check-up for non-specific symptoms, such as belching or a bloated abdomen. Among the 9 cases, there were 6 female patients and 3 male patients $(2: 1)$. The age of the patients ranged from 40-71 years, with a mean age of 52.22 years. A total of 6 tumor cases (cases 1, 2, 5, 6, 7 and 8 ) originated from the gastric body, whereas the remaining 3 originated from the fundus of the stomach (cases 3, 4 and 9; Table I). Cases 1 and 9 were concomitant with reflux esophagitis, case 2 was accompanied with duodenal ulcer, and erosive hemorrhagic gastritis and hypertension were reported in case 3 . Furthermore, type 2 diabetes and superficial gastritis were diagnosed in cases 6 and 8, respectively. No patients were reported to suffer from autoimmune disorders. The details of smoking, alcohol consumption and body mass index are listed in Table I.

Laboratory tests. No abnormalities were evident in routine and tumor marker blood tests [including carcinoembryonic antigen, $\alpha$-fetoprotein, carbohydrate antigen (CA)19-9 and CA-125]. Cases 1 and 2 presented with chronic hepatitis B virus (HBV) infection, and cases 1,3 and 8 were positive in the ${ }^{13} \mathrm{C}$ breath test and diagnosed with HP infection (Table II). Furthermore, C-reactive protein (CRP) levels were slightly elevated in 5 cases (cases 1, 2, 3, 7 and 8).

Gross examination and microscopic findings. Sections from all 9 cases revealed well-defined lumps; each section contained an isolated nodular lesion covered by intact mucosa. The maximum diameter ranged from $1.3-2.5 \mathrm{~cm}$, with a mean of $1.81 \mathrm{~cm}$. A total of 4 tumors (cases 2,3,4 and 8) were located in the lamina propria, with extension to the submucosa, whereas the remaining 5 cases $(1,5,6,7$ and 9) occurred in the submucosa (Table I).

Microscopically, the common characteristics of the 9 cases included considerable hypocellular sclerosis and wavy storiform coarse collagen infiltrated with scattered or patchy mononuclear inflammatory cells. Six cases (cases 1, 2, 4, 5, 6 and 9) exhibited a predominance of dense hyaline fibrous tissue infiltrated with many inflammatory cells and multifocal dystrophic calcifications. Psammomatous and dystrophic calcifications are indicated in Fig. 1.

Immunohistochemical staining. From the immunohistochemical examination of gastric CFT specimens, lesional cells were determined to be positive for vimentin and GPER expression. However, all 9 cases were negative for ER expression (Fig. 2).

Treatment and follow-up. A total of 8 patients were treated with ESD; only 1 patient (case 6) underwent partial gastrectomy. Following ESD or surgical treatment, all patients recovered fully. None of the 9 patients available to follow-up (mean follow-up time, 13.11 months; range, 4-25 months) have experienced local recurrence (Table I).

Literature search. In total, 25 previous studies regarding gastric CFT were identified, including 39 individual cases (Table III) (7-31). At present, there are 48 cases of gastric CFT reported in the English language literature, including the 9 cases from the present study. Among the 48 cases of gastric CFT, there were 28 female and 20 male patients, a sex ratio of $1.4: 1$. The number of female patients was more than twice that of the male patients in the patients $<50$ years of age (17 vs. 8), whereas the number was almost equal between women and men $\geq 50$ years of age (11 vs. 12; Fig. 3 ). Regarding geographical distribution of the gastric CFT patients, Asia ranked the highest (including 17 patients in China, 4 in Korea, 3 in Japan, 1 in Kuwait, 1 in Turkey and 1 in Pakistan), followed by Europe ( 7 patients in Germany, and 1 in each of Greece, Slovakia, Switzerland, France and Italy), whereas only 9 cases occurred in North America (8 patients in the USA and 1 in Canada). According to the distribution of these 48 cases, it appears that people from Asia, especially from East Asia, are more likely to suffer from this disease than people from Europe or North America, potentially due to ethnic or regional differences.

\section{Discussion}

To the best of our knowledge, the present study reported the largest case series on gastric CFTs to date. Among the 9 gastric CFT patients included in this study, 3 were infected with HP, and 2 with HBV. Due to the extremely low incidence of this type of tumor, there is no previous research considering the association between the occurrence of gastric CFT and HP or HBV. In addition, the distribution of the 48 reported cases indicated that people from East Asia may be more likely to suffer from this disease compared with people from Europe or 
Table II. Laboratory tests of 9 cases of gastric calcifying fibrous tumor.

\begin{tabular}{lccccc}
\hline $\begin{array}{l}\text { Case } \\
\text { no. }\end{array}$ & $\begin{array}{c}\text { Blood } \\
\text { routine }\end{array}$ & $\begin{array}{c}\text { Tumor } \\
\text { markers }^{\mathrm{a}}\end{array}$ & CRP & HBV & HP \\
\hline 1 & - & - & $\uparrow$ & + & + \\
2 & - & - & $\uparrow$ & + & $\mathrm{N}$ \\
3 & - & - & $\uparrow$ & $\mathrm{N}$ & + \\
4 & - & - & - & $\mathrm{N}$ & $\mathrm{N}$ \\
5 & - & - & - & $\mathrm{N}$ & $\mathrm{N}$ \\
6 & - & - & - & $\mathrm{N}$ & $\mathrm{N}$ \\
7 & - & - & $\uparrow$ & $\mathrm{N}$ & $\mathrm{N}$ \\
8 & - & - & $\uparrow$ & $\mathrm{N}$ & + \\
9 & - & - & - & $\mathrm{N}$ & $\mathrm{N}$ \\
\hline
\end{tabular}

${ }^{a}$ Tumor markers consist of carbohydrate antigen 125, carbohydrate antigen 19-9, $\alpha$-fetoprotein and carcinoembryonic antigen. CRP, C-reactive protein; HBV, hepatitis B virus; HP, H. pylori; -, in normal range; $\uparrow$, beyond normal range; + , positive result; $N$, negative result.

North America. Whether this is a coincidence requires further exploration.

At present, the etiology and pathogenesis of CFT confined to the gastric wall remain elusive $(5,11-14)$. In a previous study, cases of CFT following trauma were reported, and it has been speculated that gastric CFT may represent a localized inflammatory fibrosclerosis in response to tissue injury affecting the stomach (32). However, no prior history of any trauma or tissue injuries to the stomach, such as ulcers or perforation, were identified in the present 9 cases. Furthermore, previous studies have indicated that these tumors are true neoplasms, with the potential for non-destructive local recurrence (33), rather than a reactive process resulting from abnormal tissue healing $(5,7)$. It has also been suggested that this lesion results from an immunoglobulin (Ig)G4-associated disorder $(34,35)$; gastric CFTs may represent a stage of an IgG4-associated disorder, and steroid therapy should be included in clinical management prior to GWE or ESD (18). However, among the present 9 cases, none of the patients presented with autoimmune disorders such as primary biliary cirrhosis, chronic atrophic gastritis, inflammatory bowel disease or IgG4-associated pancreatitis.

The present study demonstrated that gastric CFT may have a female predominance (female:male, 2:1), which is consistent with the previous literature $(1.27: 1)(5,13)$. Including the 9 cases in the current study and the 39 from previous studies, the sex ratio is 1.4:1. Following age stratification, a marked difference was identified in the sex ratio of patients above or below age 50. This suggests that this rare tumor is more common in female patients, particularly premenopausal women. Based on the marked difference in sex ratio before and after age 50, it is speculated that estrogen may serve a role in the occurrence and progression of gastric CFT.

As estrogen exerts its effects via binding GPER or ER, the ER and GPER expression status of the patient samples was detected with immunohistochemistry. Immunostaining was performed on samples from 9 cases; cells from the lesions exhibited positive immunoreactivity for GPER, but no immunoreactivity for ER. 

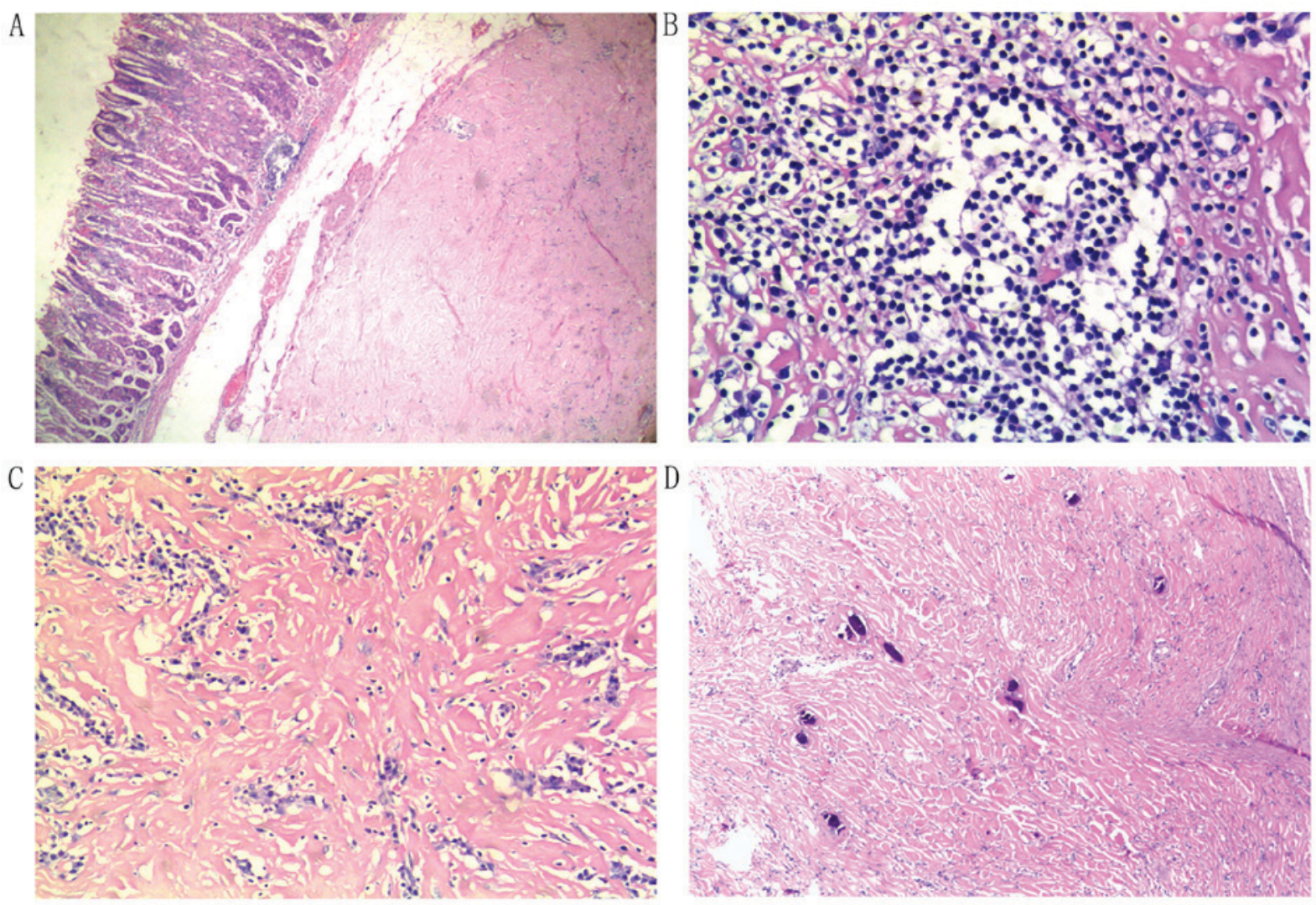

Figure 1. Microscopic features of gastric calcifying fibrous tumor. (A) The mass was well-circumscribed and located in the lamina propria (H\&E staining; original magnification, $\mathrm{x} 40$ ). (B and C) Lymphoplasmacytic inflammatory infiltrate was present throughout the tumor and focally formed lymphoid follicles (H\&E staining; B, original magnification, $\mathrm{x} 200$; C, original magnification, $\mathrm{x} 100$ ). (D) Psammoma and dystrophic bodies are visible in this case (H\&E staining; original magnification, $\mathrm{x} 100)$. H\&E, hematoxylin and eosin.
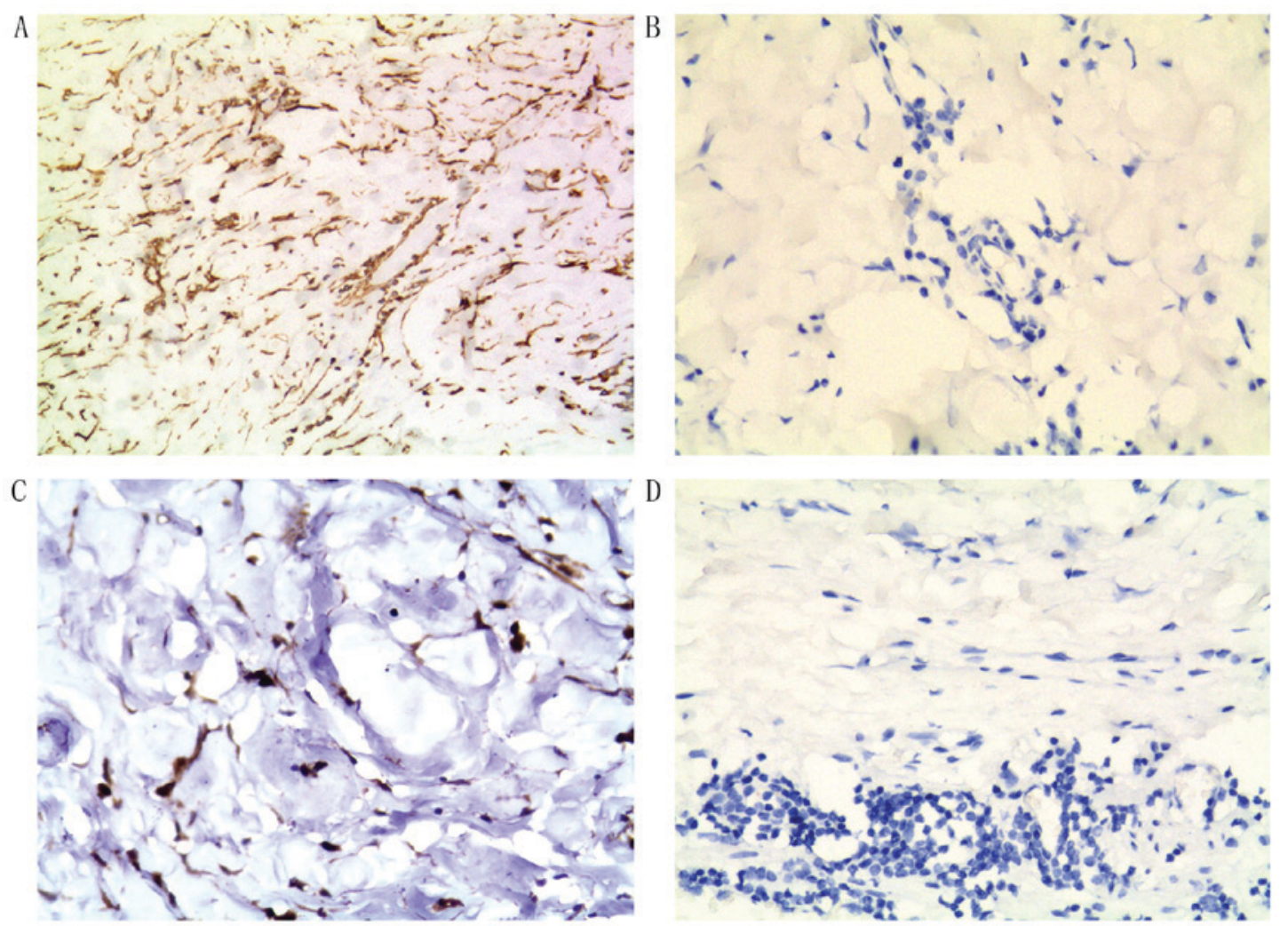

Figure 2. Immunohistochemical features of gastric calcifying fibrous tumor (hematoxylin and eosin staining; original magnification, $\mathrm{x} 200$ ). (A) Vimentin expression was positive; (B) estrogen receptor expression was negative; (C) G protein-coupled estrogen receptor expression was positive. (D) Immunohistochemical negative control. 
Table III. Clinicopathologic features of 39 cases of gastric calcifying fibrous tumor from previous studies.

\begin{tabular}{|c|c|c|c|c|c|c|c|c|c|}
\hline Author & Case no. & Country & $\begin{array}{c}\text { Age } \\
\text { (years) }\end{array}$ & Sex & Site & Layer & Size $(\mathrm{cm})$ & Treatment & (Refs.) \\
\hline Tanaka et al & 10 & Japan & 43 & Female & NA & Submucosa & NA & Local excision & (7) \\
\hline Liu and Song & 11 & China & 32 & Male & Body & Submucosa & $3.0 \times 2.0 \times 2.0$ & Local excision & (8) \\
\hline Nascimento et al & 12 & USA & 64 & Male & NA & NA & 1.1 & Local excision & (9) \\
\hline Nascimento et al & 13 & USA & 65 & Female & NA & NA & 0.8 & Local excision & (9) \\
\hline Kitamura et al & 14 & Japan & 44 & Female & Body & Submucosa & $3 \times 2.6 \times 2.4$ & LWGR & (10) \\
\hline Yun et al & 15 & Korea & 59 & Male & Fundus & Lamina propria & $3.9 \times 2.7$ & LWGR & (11) \\
\hline Agaimy et al & 16 & Germany & 51 & Male & Body & Lamina propria & 2.0 & Local excision & (12) \\
\hline Agaimy et al & 17 & Germany & 77 & Female & Body & Lamina propria & 1.0 & Local excision & (12) \\
\hline Agaimy et al & 18 & Germany & 59 & Female & Body & Lamina propria & 3.0 & Local excision & (12) \\
\hline Agaimy et al & 19 & Germany & 53 & Male & Antrum & $\begin{array}{l}\text { Muscularis } \\
\text { mucosae }\end{array}$ & 2.0 & Local excision & (12) \\
\hline Agaimy et al & 20 & Germany & 40 & Male & Body & Lamina propria & 2.0 & Local excision & (12) \\
\hline Agaimy et al & 21 & Germany & 42 & Female & Body & Lamina propria & 3.0 & Local excision & (12) \\
\hline Agaimy et al & 22 & Germany & 51 & Male & Body & Lamina propria & 2.2 & Local excision & (12) \\
\hline Pezhouh et al & 23 & USA & 70 & Female & NA & Submucosa & 1.3 & NA & (13) \\
\hline Pezhouh et al & 24 & USA & 39 & Male & NA & Submucosa & 1.5 & NA & (13) \\
\hline Pezhouh et al & 25 & USA & 51 & Female & NA & Serosa & 0.5 & NA & (13) \\
\hline Pezhouh et al & 26 & USA & 40 & Female & NA & Submucosa & 2.5 & NA & (13) \\
\hline Pezhouh et al & 27 & USA & 65 & Female & NA & Submucosa & 1.5 & NA & (13) \\
\hline Shi et al & 28 & China & 58 & Female & Body & Lamina propria & 2.3 & ESD & (14) \\
\hline Shi et al & 29 & China & 46 & Female & Body & Lamina propria & 1.0 & ESD & (14) \\
\hline Shi et al & 30 & China & 61 & Male & Body & Lamina propria & 2.0 & EFR & (14) \\
\hline Shi et al & 31 & China & 53 & Male & Antrum & Lamina propria & 2.5 & EFR & (14) \\
\hline Fan et al & 32 & China & 49 & Male & Body & NA & $2.0 \times 2.5$ & Local excision & (15) \\
\hline Ogasawara et al & 33 & Japan & 37 & Female & Body & Lamina propria & 1.0 & ESD & (16) \\
\hline $\begin{array}{l}\text { George and } \\
\text { Abdeen }\end{array}$ & 34 & Kuwait & 27 & Female & Fundus & Submucosa & $1.5 \times 1 \times 0.5$ & Surgery & (17) \\
\hline Zhang et al & 35 & China & 55 & Female & Body & Submucosa & 2.0 & ESD & (18) \\
\hline Vasilakaki et al & 36 & Greece & 60 & Male & Body & Lamina propria & $1.0 \mathrm{x} 0.8$ & Local excision & (19) \\
\hline Attila et al & 37 & Canada & 47 & Female & Body & Mucosa & $2.0 \times 2.0$ & LWGR & (20) \\
\hline Elpek et al & 38 & Turkey & 25 & Man & Body & Submucosa & $1 \times 0.9 \times 0.5$ & Urgent surgery & (21) \\
\hline Puccio et al & 39 & Italy & 49 & Female & Body & NA & NA & LWGR & (22) \\
\hline Štofíková et al & 40 & Slovakia & 68 & Female & Body & Submucosa & 3.2 & Local excision & (23) \\
\hline Abbadessa et al & 41 & USA & 17 & Male & NA & NA & NA & LWGR & (24) \\
\hline Lee et al & 42 & Korea & 49 & Man & Body & Submucosa & 3.0 & $\begin{array}{l}\text { Laparoscopic } \\
\text { and endoscopic } \\
\text { excision }\end{array}$ & (25) \\
\hline Liu et al & 43 & China & 37 & Female & NA & NA & NA & $\begin{array}{l}\text { Endoscopic } \\
\text { resection }\end{array}$ & (26) \\
\hline Lee $e t a l$ & 44 & Korea & 5 & Female & Fundus/body & NA & $4.0 \times 3.0$ & Total excision & (27) \\
\hline Delbecque et al & 45 & Switzerland & 63 & Male & Body & Submucosa & $2 \times 1.5 \times 1.5$ & Local excision & (28) \\
\hline Azam et al & 46 & Pakistan & 13 & Male & Fundus & NA & $8.0 \times 6.0 \times 6.0$ & Surgery & (29) \\
\hline Chatelain et al & 47 & France & 50 & Female & Body & NA & 2.0 & Local excision & (30) \\
\hline Jang et al & 48 & Korea & 43 & Female & Body & Submucosa & $3.0 \times 2.0$ & LGWR & (31) \\
\hline
\end{tabular}




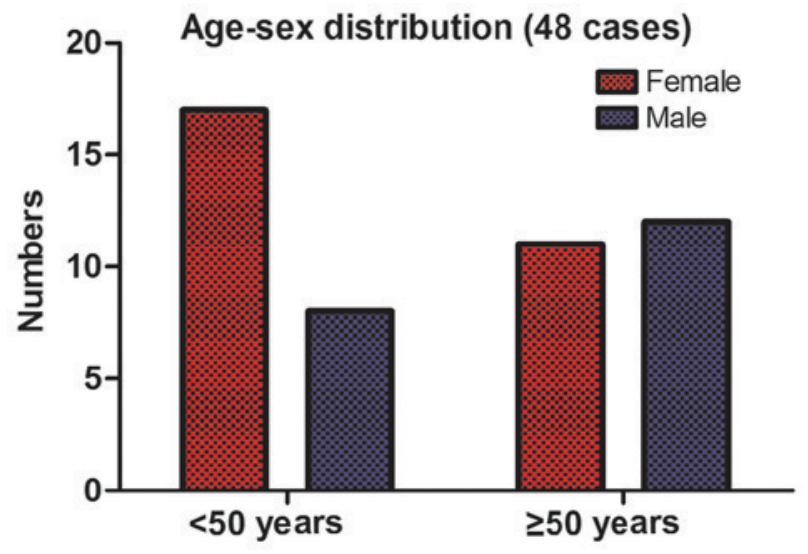

Figure 3. Age-sex distribution of all 48 reported gastric calcifying fibrous tumor cases. The number of female patients was twice that of male patients $<50$ years of age, whereas the number was almost equal between women and men $\geq 50$ years of age.

ER, also known as classical steroid receptor, is a ligand-activated nuclear transcription factor that recognizes cis-acting hormone response elements in the promoters of hormonally regulated genes (36). The present results revealed that the ER mediation of the classical genomic signal pathway was not associated with the potential effects of estrogen on the pathogenesis of gastric CFTs. Thus, any effects of estrogen on this tumor are likely to be mediated by an alternative pathway. GPER is a membrane-associated estrogen receptor that can mediate both the rapid estrogen and traditional genomic estrogen response signal pathways (36). A previous study demonstrated that estrogen exerts its physiological effects through GPER in normal stromal cells (37). Furthermore, the activation of GPER signaling by estrogen has been reported to stimulate the formation of fibers in fibroblasts (38). Therefore, it can be hypothesized that the activation of GPER by estrogen may promote the formation of fibers, and even fibrosis, in the stomach. However, more basic research regarding the effects of estrogen in gastric CFTs will be required in the future to confirm this hypothesis.

Gastric CFT is a benign lesion with a good prognosis that demonstrates a predilection for female patients, especially premenopausal women. Estrogen mediated by GPER rather than ER may serve a role in this female predominance. The association between gastric CFTs and HP or HBV infection remains to be elucidated in high-calibrated studies.

\section{Acknowledgements}

Not applicable.

\section{Funding}

The present study was supported by grants from the National Natural Science Foundation of China (grant nos. 81372551 and 81602535).

\section{Availability of data and materials}

The data generated during the present study are available from the corresponding author on reasonable request.

\section{Authors' contributions}

ST and WD conceived and designed the present study; XP performed the literature review; ZZ assessed the immunohistochemical results; ST wrote the manuscript. All authors read and approved the final manuscript.

\section{Ethics approval and consent to participate}

The present study was approved by the Institutional Review Board of the Renmin Hospital of Wuhan University (Wuhan, China). All patients included in this study provided written informed consent.

\section{Patient consent for publication}

Not applicable.

\section{Competing interests}

The authors declare that they have no competing interests.

\section{References}

1. Rosenthal NS and Abdul-Karim FW: Childhood fibrous tumor with psammoma bodies. Clinicopathologic features in two cases. Arch Pathol Lab Med 112: 798-800, 1988.

2. Pinkard NB, Wilson RW, Lawless N, Dodd LG, McAdams HP, Koss MN and Travis WD: Calcifying fibrous pseudotumor of pleura: A report of three cases of a newly described entity involving the pleura. Am J Clin Pathol 105: 189-194, 1996.

3. Van Dorpe J, Ectors N, Geboes K, D'Hoore A and Sciot R: Is calcifying fibrous pseudotumor a late sclerosing stage of inflammatory myofibroblastic tumor? Am J Surg Pathol 23: 329-335, 1999.

4. Im S, Jung JH, Yoo C, Choi HJ, Yoo J and Kang CS: Calcifying fibrous tumor presenting as rectal submucosal tumor: First case reported in rectum. World J Surg Oncol 12: 28, 2014.

5. Chorti A, Papavramidis TS and Michalopoulos A: Calcifying fibrous tumor. Medicine (Baltimore) 95: e3690, 2016.

6. Ma J, Guo X, Zhang J, Wu D, Hu X, Li J, Lan Q, Liu Y and Dong W: PTEN gene induces cell invasion and migration via regulating AKT/GSK-3 $\beta / \beta$-catenin signaling pathway in human gastric cancer. Dig Dis Sci 62: 3415-3425, 2017.

7. Tanaka H, Baba Y, Matsusaki S, Isono Y, Saito T, Sase T, Okano H, Mukai K, Taoka H and Murata T: A case of calcifying fibrous tumor in the abdominal wall, morphologically resembling a gastric submucosal tumor. Nihon Shokakibyo Gakkai Zasshi 111: 529-534, 2014 (In Japanese).

8. Liu DD and Song LH: Calcifying fibrous tumor in gastric wall: Report of a case. Zhonghua Bing Li Xue Za Zhi 38: 346-347, 2009 (In Chinese).

9. Nascimento AF, Ruiz R, Hornick JL and Fletcher CD: Calcifying fibrous 'pseudotumor': Clinicopathologic study of 15 cases and analysis of its relationship to inflammatory myofibroblastic tumor. Int J Surg Pathol 10: 189-196, 2002.

10. Kitamura H, Takehara A, Shimada M, Moriyama H, Saito K, Hada M, Shibahara K, Sasaki M, Konishi K and Maeda Y: Calcifying fibrous tumor of the gastric wall. Nippon Shokaki Geka Gakkai Zasshi 42: 1773-1778, 2009.

11. Yun JK, Park HS, Moon WS, Lee H and Chan YK: Calcifying fibrous tumor of the stomach: A case report. J Korean Surg Soc 83: 56-59, 2012.

12. Agaimy A, Bihl MP, Tornillo L, Wünsch PH, Hartmann A and Michal M: Calcifying fibrous tumor of the stomach: Clinicopathologic and molecular study of seven cases with literature review and reappraisal of histogenesis. Am J Surg Pathol 34: 271-278, 2010.

13. Pezhouh MK, Rezaei MK, Shabihkhani M, Ghosh A, Belchis D, Montgomery EA and Voltaggio L: Clinicopathologic study of calcifying fibrous tumor of the gastrointestinal tract: A case series. Hum Pathol 62: 199-205, 2017. 
14. Shi Q, Xu MD, Chen T, Zhong YS, Zhou PH, Wu HF and Yao LQ Endoscopic diagnosis and treatment of calcifying fibrous tumors. Turk J Gastroenterol 25 (Suppl 1): S153-S156, 2014.

15. Fan SF, Yang H, Li Z and Teng GJ: Gastric calcifying fibrous pseudotumour associated with an ulcer: Report of one case with a literature review. Br J Radiol 83: e188-e191, 2010.

16. Ogasawara N, Izawa S, Mizuno M, Tanabe A, Ozeki T, Noda H, Takahashi E, Sasaki M, Yokoi T and Kasugai K: Gastric calcifying fibrous tumor removed by endoscopic submucosal dissection. World J Gastrointest Endosc 5: 457-460, 2013.

17. George SA and Abdeen S: Gastric calcifying fibrous tumor resembling gastrointestinal stromal tumor: A case report. Iran J Pathol 10: 306-309, 2015.

18. Zhang H, Zhu J and Ding S: Gastric calcifying fibrous tumor: A case of suspected immunoglobulin G4-related gastric disease. Saudi J Gastroenterol 21: 423-426, 2015.

19. Vasilakaki T, Skafida E, Tsavari A, Arkoumani E, Koulia K, Myoteri D, Grammatoglou X, Moustou E, Firfiris N and Zisis D: Gastric calcifying fibrous tumor: A very rare case report. Case Rep Oncol 5: 455-458, 2012

20. Attila T, Chen D, Gardiner GW, Ptak TW and Marcon NE: Gastric calcifying fibrous tumour. Can J Gastroenterol 20: 487-489, 2006

21. Elpek GO, Küpesiz GY and Ogüs M: Incidental calcifying fibrous tumor of the stomach presenting as a polyp. Pathol Int 56 : 227-232, 2006.

22. Puccio F, Solazzo M, Marciano P and Benzi F: Laparoscopic resection of calcifying fibrous pseudotumor of the gastric wall. Surg Endosc 15: 1227, 2001.

23. Štofíková M, Rychlý B, Bocko J and Daniš D: Submucosal calcifying fibrous tumor of the stomach: A case report. Cesk Patol 52: 164-167, 2016

24. Abbadessa B, Narang R, Mehta R, Martinez J, Leitman IM Jr and Karpeh M: Laparoscopic resection of a gastric calcifying fibrous pseudotumor presenting with ulceration and hematemesis in a teenage patient. J Surg Radiol 4: 48-51, 2012.

25. Lee S, Jahng J and Han W: Gastric calcifying fibrous tumor manifesting as a subepithelial tumor. J Gastrointest Surg 22: $1127-1129,2018$

26. Liu Z, Guo J, Ren W, Sun S, Tang S and Xie L: A gastric calcifying fibrous pseudotumor detected by transabdominal ultrasound after oral administration of an echoic cellulose-based gastrointestinal ultrasound contrast agent. Ultraschall Med 35: 181-183, 2014.

27. Lee D, Suh YL and Lee SK: Calcifying fibrous pseudotumour arising in a gastric inflammatory myofibroblastic tumour. Pathology 38: 588-591, 2006.
28. Delbecque K, Legrand M, Boniver J,Lauwers GY and de Leval L: Calcifying fibrous tumour of the gastric wall. Histopathology 44 399-400, 2004

29. Azam M, Husen YA and Pervez S: Calcifying fibrous pseudotumor in association with hyaline vascular type Castleman's disease. Indian J Pathol Microbiol 52: 527-529, 2009.

30. Chatelain D, Lauzanne P, Yzet T, Guernou M, Delcenserie R, Regimbeau JM and Sevestre H: Gastric calcifying fibrous pseudotumor, a rare mesenchymal tumor of the stomach. Gastroenterol Clin Biol 32: 441-444, 2008 (In French).

31. Jang EY, Kim HJ, Kim JH, Lee SO, Choi K and Lee HJ: A case of gastric calcifying fibrous tumor presenting as a subepithelial tumor. Korean J Helicob Upper Gastrointest Res 13: 248-251, 2013.

32. Zámecník M, Dorociak F and Veselý L: Calcifying fibrous pseudotumor after trauma. Pathol Int 47: 812, 1997.

33. Tseng IT, Chen ST, Huang ZZ, Tung HI and Ker CK: Multiple calcifying fibrous tumors in the small intestine and the mesentery. Formosan J Surg 45: 33-36, 2012.

34. Nagai Y, Hayama N, Kishimoto NH, Furuya M, Takahashi Y, Otsuka M, Miyazaki M and Nakatani Y: Predominance of $\lg \mathrm{G}^{+}$ plasma cells and CD68 positivity in sclerosing angiomatoid nodular transformation (SANT). Histopathology 53: 495-498, 2008.

35. Yamamoto H, Yamaguchi H, Aishima S, Oda Y, Kohashi K, Oshiro Y and Tsuneyoshi M: Inflammatory myofibroblastic tumor versus IgG4-related sclerosing disease and inflammatory pseudotumor: A comparative clinicopathologic study. Am J Surg Pathol 33: 1330-1340, 2009

36. Prossnitz ER, Arterburn JB, Smith HO, Oprea TI, Sklar LA and Hathaway HJ: Estrogen signaling through the transmembrane $\mathrm{G}$ protein-coupled receptor GPR30. Annu Rev Physiol 70: 165-190, 2008

37. Prossnitz ER and Hathaway HJ: What have we learned about $\mathrm{G}$ protein-coupled estrogen receptor function in physiology and disease from knockout mice? J Steroid Biochem Mol Biol 153: 114-126, 2015.

38. Mao S, Wang Y, Zhang M and Hinek A: Phytoestrogen, tanshinone IIA diminishes collagen deposition and stimulates new elastogenesis in cultures of human cardiac fibroblasts. Exp Cell Res 323: 189-197, 2014.

This work is licensed under a Creative Commons Attribution-NonCommercial-NoDerivatives 4.0 International (CC BY-NC-ND 4.0) License. 